Research Article

\title{
A Comparative Study on the Wettability of Two Coal Samples during Deep Burial Metamorphism
}

\author{
Guochao Yan $(\mathbb{D}$, Longjian Bai $(\mathbb{D}$, Jianping Feng, and Zhiqiang Zhang $(\mathbb{D}$ \\ College of Mining Engineering, Taiyuan University of Technology, Taiyuan, Shanxi, China \\ Correspondence should be addressed to Longjian Bai; bailongjian321@163.com and Zhiqiang Zhang; donaldzhang@foxmail.com
}

Received 26 November 2019; Accepted 22 January 2020; Published 13 April 2020

Academic Editor: Christos Kordulis

Copyright (C) 2020 Guochao Yan et al. This is an open access article distributed under the Creative Commons Attribution License, which permits unrestricted use, distribution, and reproduction in any medium, provided the original work is properly cited.

In order to investigate the effect of deep burial metamorphism on the wettability of coal during deep burial metamorphism, a superficial coal sample $(\sim 90 \mathrm{~m})$ and a deep coal sample $(\sim 490 \mathrm{~m})$ collected from two main mining seams were selected to simulate the deep burial metamorphism process. The wettability of two coal samples during deep burial metamorphism was investigated by X-ray photoelectron spectroscopy (XPS), FTIR, zeta potential, and contact angle measurements. Besides, comprehensive DLVO interaction analyses between two coal samples from different mining depths were carried out through the zeta potentials measurements under different $\mathrm{pH}$ values. The XPS results demonstrate that the content of surface oxygen atom and oxygencontaining functional group for superficial coal tends to be higher than that of deep coal. The FTIR results indicate that the peak intensity of oxygen-containing functional groups for the superficial is higher than that of deep coal, implying the stronger surface hydrophobicity of deep coal compared to superficial coal. The contact angle of superficial coal is lower than that of deep coal. The zeta potential and DLVO theory analyses of superficial particles and deep coal particles indicate that deep burial metamorphism process might be favorable for bubble-particle collision and attachment, while might be unfavorable for the wetting process oppositely. Based on the surface chemistry characterization and theory analyses, this study is expected to give a theoretical insight into the efficient processing or dedusting process of coals experiencing different deep burial metamorphism processes in the future.

\section{Introduction}

It is well known that coals experienced successive plate tectonic movements during the coal-forming periods. These plate tectonic movements and orogeny caused collision, uplift, depression, extrusion, tension, faulting, magmatic activity, and other geological movements, making the coal seams to deform, slip, and shear, and thus the coal thickness, coal structure, and the degree of coal metamorphism changed [1]. Therefore, the degree of coal metamorphism varies in different mining depths, resulting in a different wettability of the coal dust [2]. For this reason, it is necessary to study the effects of the physical chemistry characteristics of coal dust with different metamorphic degrees on wetting behavior.

Researchers have been devoted to investigating the coal surface properties. The investigation of hydrophobicity/ wettability of the coal surface has been widely used in modern coal processing, e.g., the flotation and dedusting process [3-9]. Coal dust poses a great threat to the safety of coal production process and the health of miners. On the one hand, coal dust could potentially cause mine explosion, resulting in severe accidents. On the other hand, miners who are frequently exposed to the coal dust-contaminated work environment are highly vulnerable to pneumoconiosis. Since the 1950s, about 727000 cases of pneumoconiosis in coal mines have been reported. From 2000 to 2014, 480 mine workers died of coal-dust-triggered explosions $[3,10]$. The wet dust removal method, such as coal seam water injection or spraying fan, is one of the most commonly used means for dedusting in China. Due to the poor wettability of the coal dust, the insignificant dedusting effect of the wet dust removal method was observed in the underground workplace. Therefore, to realize higher dust removal efficiency, the study 
on the mechanism of coal dust wettability is of great importance.

The coal surface properties can be described qualitatively using three kinds of states: hydrophilic, weakly hydrophobic, and strongly hydrophobic [11]. The hydrophilicity or wettability of coal dust plays a leading role in the dust suppression effect. Wetting agents could enhance the hydrophilicity of coal dust by decreasing the surface tension of liquids $[12,13]$. Glanville et al. found that the surfactant concentration, granularity of coal dust, temperature, and area of the wetting surface have a great influence on the rate of surface wetting [14-16]. Osasere Orumwense concluded that the electrolyte coagulants and flocculants modified the coal surface properties through physical interaction. Additionally, it was shown that the hydrophilicity of coal dust increased with a rise in the polarity of the surfactants [17].

In this paper, the effect of deep burial metamorphism on the wettability of coal during deep burial metamorphism was investigated. Two coal samples collected from two main mining seams of different depths were used to simulate the deep burial metamorphism process. XPS, FTIR, zeta potential, and contact angle measurements were used to characterize the wettability of two coal samples during deep burial metamorphism. Additionally, comprehensive DLVO interaction analyses between two coal samples from different mining depths were carried out through the measured zeta potentials under different $\mathrm{pH}$ values, which is expected to give a theoretical insight into the efficient processing or dedusting process of coals experiencing different deep burial metamorphism processes in the future. A theoretical insight into the efficient processing or dedusting process of coals experiencing different deep burial metamorphism processes was expected based on the experimental and theoretical analyses in this study.

\section{Materials and Methods}

2.1. Materials. In this study, two coal samples were collected from two different coal seams of different mining depths in Shanxi province, China. Precisely, for each sample, at least 30 sampling points were chosen, and the samples were fully mixed, denoted as Coal 1( $\sim 90 \mathrm{~m})$ and Coal $2(\sim 490 \mathrm{~m})$. The proximate analyses of two coal samples are presented in Table 1 , where $M_{a d}$ is the moisture content, $V_{a d}$ the volatile matter content, $\mathrm{FC}_{\mathrm{ad}}$ the fixed carbon content, and $\mathrm{A}_{\mathrm{ad}}$ is the ash content on an air dry basis. As presented in Table 1, the ash content of two coal samples is similar.

2.2. XPS Measurements. As a surface-sensitive spectroscopic technique, XPS is capable of analyzing chemical information on the coal surface. The wettability of the coal surface mirrors the proclivity of the surface to contact water. By means of XPS, the quantitative information of coal surface elements and hydrophobic/hydrophilic groups can be obtained to study the coal wettability.

The XPS measurement was performed at room temperature under vacuum condition using a multifunctional photoelectron spectrometer (ESCALAB 250Xi, American).
Table 1: Proximate analysis of coal samples from different coal seams.

\begin{tabular}{lcccc}
\hline Coal types & $\mathrm{M}_{\mathrm{ad}}$ & $\mathrm{V}_{\mathrm{ad}}$ & $\mathrm{FC}_{\mathrm{ad}}$ & $\mathrm{A}_{\mathrm{ad}}$ \\
\hline Coal 1 & 1.46 & 13.67 & 59.68 & 25.19 \\
Coal 2 & 0.68 & 9.88 & 65.43 & 24.01 \\
\hline
\end{tabular}

The binding energies are corrected using the $\mathrm{C} 1 \mathrm{~s}$ hydrocarbon peak with a reference of $284.8 \mathrm{eV}$. In the XPS spectra, the abscissa represents the binding energy and the ordinate stands for the electrical counter. The XPS Peak fit software was used for the peak fitting. During all the analyses, the spot size was $900 \mu \mathrm{m}$, and the take-off angle of the photoelectrons was $90^{\circ}$. The XPS survey spectra were recorded under the $\mathrm{Al}$ Ka radiation $(\mathrm{h} v=1486.6 \mathrm{eV})$ with the energy step size of $1.00 \mathrm{eV}$ and the pass energy of $100 \mathrm{eV}$.

2.3. FTIR Analysis. FTIR spectrums of two coal samples were obtained with $\mathrm{KBr}$ pellets prepared with two coal samples ground with $\mathrm{KBr}$ in a mortar. For the FTIR analyses, a Fourier Transform Infrared Spectroscopy Vertex $80 \mathrm{v}$ (Bruker, Germany) was used, and the spectrum was obtained at $2 \mathrm{~cm}^{-1}$ resolution between 4000 and $400 \mathrm{~cm}^{-1}$.

2.4. Zeta Potential Measurements. The zeta potential measurements were carried out using a Zetasizer (Malvern Nano Z, UK). $0.05 \mathrm{~g}$ coal samples were conditioned with $100 \mathrm{ml}$ DI water for $5 \mathrm{~min}(0.05 \% \mathrm{w} / \mathrm{v}$ solids ratio). The coarse particles were allowed to settle down, and the supernatant solution containing fine particles was used for the zeta potential measurements which were repeated at least 4 times.

2.5. Contact Angle Measurements. Prior to the contact angle measurement, the coal samples were pressed to plates. A contact angle analyzer (JC2000D) was applied to measure the contact angle between a water droplet and the surface of the coal plate. The contact angles were recorded when the water droplet contacts instantly with the coal plate.

\section{Results and Discussion}

3.1. XPS Analysis. The molar content percentage of carbonyl and carboxyl groups can be calculated in terms of the atom concentration in the XPS full scan spectrum. Moreover, the relative content of surface oxygen-containing functional groups can be derived from the peak-split results. Due to the limited measurement precision of XPS, no significant difference can be observed between the hydroxyl group and the ether group. $\mathrm{C} 1 \mathrm{~s}$ peaks for two coal samples are shown in Figures 1 and 2. XPS Peak fit software is employed to split and fit the XPS spectrogram at $1 \mathrm{~s}$. The spectra were fitted with four Gaussian-shaped peaks that occur at 284.6, 285.3, 286.3 , and $289.0 \mathrm{eV}$. The peak at $284.6 \mathrm{eV}$ is corresponding to $\mathrm{C}-\mathrm{C}$ or $\mathrm{C}-\mathrm{H}$ bond. The peak at $285.3 \mathrm{eV}$ represents the contribution from chemical groups of $\mathrm{C}-\mathrm{O}-\mathrm{C}$ and $\mathrm{C}-\mathrm{OH}$. The peak at $286.3 \mathrm{eV}$ and $289.0 \mathrm{eV}$ correspond to the chemical groups of carbon double bonded to oxygen and carbon double bonded to oxygen and also single bonded to 


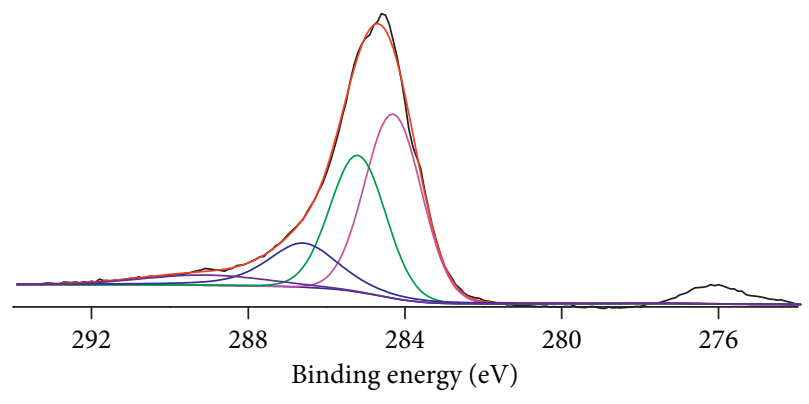

Figure 1: C1 s peaks for Coal 1.

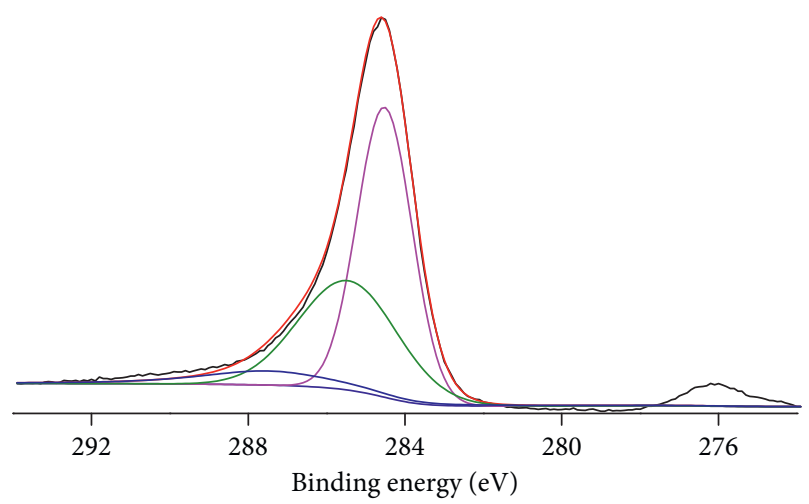

Figure 2: C1 s peaks for Coal 2.

another oxygen, namely, $\mathrm{C}=\mathrm{O}$ and $\mathrm{O}=\mathrm{C}-\mathrm{O}$, respectively [18-20]. Since both functional groups bear an oxygen atom, an equation regarding the oxygen in the $\mathrm{C}-\mathrm{O}$ bond could be established from the peak-split result. Additionally, another equation concerning two ether carbon atoms and one hydroxyl carbon in the C-O bond can be formulated from the conservation of carbon. According to the two equations, the relative molar content of surface oxygen-containing functional groups can be calculated, as shown in Table 2 .

As shown in Table 2, there are four types of oxygenbearing functional groups on the coal surface: carboxyl group $(\mathrm{O}=\mathrm{C}-\mathrm{O})$, carbonyl group $(\mathrm{C}=\mathrm{O})$, hydroxyl $(\mathrm{C}-\mathrm{OH})$, and carbon-oxygen single bond (C-O-C), and these functional groups belong to hydrophilic groups. In addition, the main hydrophobic functional groups are $\mathrm{C}-\mathrm{C}$ and $\mathrm{C}-\mathrm{H}$. The content of hydrophobic groups (C-C and C-H) of Coal 1 surface is $44.85 \%$, while the content of hydrophobic groups of Coal 2 surface is $54.57 \%$. Nonetheless, the contents of hydrophilic groups $(\mathrm{C}-\mathrm{O}-\mathrm{C}, \mathrm{C}-\mathrm{OH}, \mathrm{C}=\mathrm{O}$, and $\mathrm{O}=\mathrm{C}-\mathrm{O}$ ) of Coal 1 surface are all higher than the contents of hydrophilic groups of Coal 2 surface.

For the oxygen-containing functional groups, the carboxyl group and the hydroxyl group are regarded as the major contributors to the wettability of the coal surface $[21,22]$. Based on the data in Table 2, it was found that two coal samples exhibited different proportions of hydroxyl and carboxyl on the surface. Obviously, the contents of surface hydroxyl and carboxyl for the Coal 2 are much higher than those of Coal 1. The surface oxygen-bearing functional groups of various coal samples exhibit the same form with
TABle 2: Fraction of $\mathrm{C}$ on two coal samples (relative \% of $\mathrm{C} 1 \mathrm{~s}$ ).

\begin{tabular}{lcccc}
\hline $\begin{array}{l}\text { Coal } \\
\text { types }\end{array}$ & $\begin{array}{c}\mathrm{C}-\mathrm{C}, \mathrm{C}-\mathrm{H} \\
(\%)\end{array}$ & $\begin{array}{c}\mathrm{C}-\mathrm{O}-\mathrm{C}, \mathrm{C}-\mathrm{OH} \\
(\%)\end{array}$ & $\begin{array}{c}\mathrm{C}=\mathrm{O} \\
(\%)\end{array}$ & $\begin{array}{c}\mathrm{O}=\mathrm{C}-\mathrm{O} \\
(\%)\end{array}$ \\
\hline Coal 1 & 44.66 & 33.94 & 15.78 & 5.62 \\
Coal 2 & 55.02 & 36.56 & 8.42 & 0 \\
\hline
\end{tabular}

relatively varying contents, resulting in the difference in the surface wettability. Moreover, the hydrophilic chemical groups on the coal surface can be wetted by water much easier than the hydrophobic chemical groups, since the hydrophilic chemical groups can be bonded with water by hydrogen bond. As a result, the hydrophobicity of Coal 2 tends to be higher than Coal 1, and the deep burial metamorphism might increase the hydrophobicity of coal.

3.2. FTIR Analysis. The FTIR spectra of two coal samples are shown in Figure 3. The peak near $3450 \mathrm{~cm}^{-1}$ is corresponding to the broad infrared absorption band of phenolic/ alcoholic hydroxyl groups in coal molecules due to the formation of hydrogen bond between $\mathrm{O}-\mathrm{H}$ groups [19]. The peak near $3030 \mathrm{~cm}^{-1}$ derives from $\mathrm{C}-\mathrm{H}$ stretching vibration in benzene ring. The peaks at near 2920 and $2855 \mathrm{~cm}^{-1}$ represent the methylene group $\left(-\mathrm{CH}_{2}-\right)$ in saturated aliphatic hydrocarbon, which are caused by the $\mathrm{C}-\mathrm{H}$ antisymmetric and symmetric stretching vibration of the methylene group $[6,7]$. Also, the absorption of the peak at $1600 \mathrm{~cm}^{-1}$ derives from $\mathrm{C}=\mathrm{C}$ stretching vibration in benzene ring, which is a characteristic absorption peak to aromatic hydrocarbons [8]. The peak at near $1440 \mathrm{~cm}^{-1}$ is for the methylene group due to $\mathrm{CH}_{2}$ bending vibration when the methylene group is associated with unsaturated groups or strong electronegative atoms, such as $\mathrm{Cl}$ and $\mathrm{O}$. The peak at near $1375 \mathrm{~cm}^{-1}$ is the characteristic infrared absorption band of the methyl group $\left(-\mathrm{CH}_{3}\right)$ caused by $\mathrm{CH}_{3}$ symmetric bending vibration [6]. Peaks during $1010-1030 \mathrm{~cm}^{-1}$ may be attributed to Si-O-Si groups [23]. The peaks between $700 \mathrm{~cm}^{-1}$ and $900 \mathrm{~cm}^{-1}$ are the benzene rings.

The results indicate that the intensities of the peaks at $3450 \mathrm{~cm}^{-1}$ and $1030 \mathrm{~cm}^{-1}$ of Coal 1 are higher than those of Coal 2, and the corresponding functional group is hydrophilic, whereas the absorbance of peaks near 3030, 2850, 1438,1380 , and $700-900 \mathrm{~cm}^{-1}$ of Coal 2 is significantly higher than that of Coal 1 , and the corresponding functional group is hydrophobic. The content of carbonyl groups of two coal samples was well consistent with the results of XPS analysis.

3.3. Zeta Potential Measurements. The zeta potential is another surface property that affects bubble-particle collision and attachment processes [24]. Electrostatic attraction exists between oppositely charged particles and bubbles and promotes bubble-particle collision and attachment, whilst electrostatic repulsion exists between identically charged particles and bubbles and hinders bubble-particle collision and attachment [25]. The zeta potential of two coal samples and air bubbles as a function of $\mathrm{pH}$ was measured in DI water first, and results are shown in Figure 4. It should be 


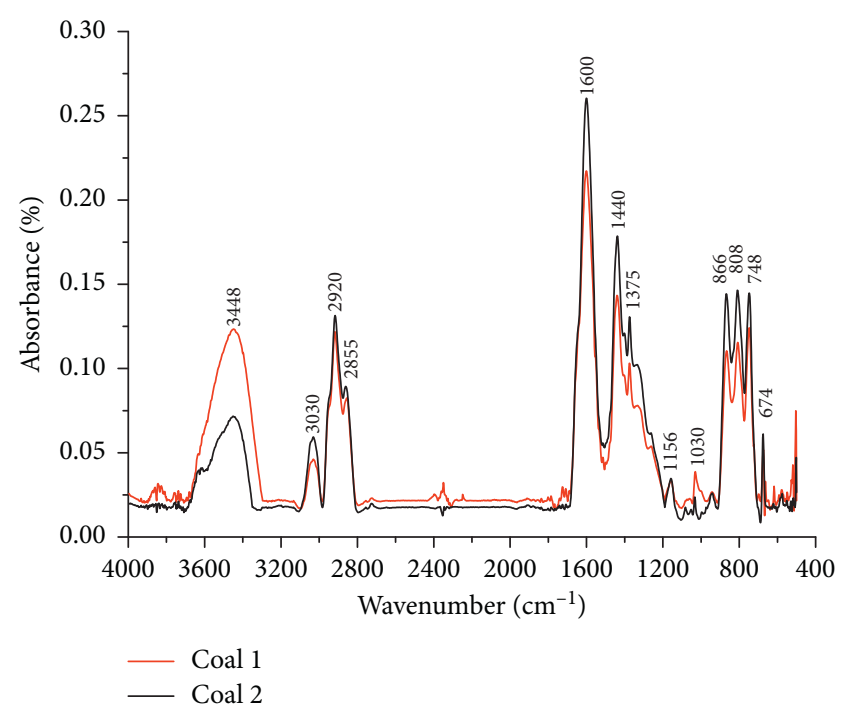

FIgURE 3: FTIR spectra of two coal samples.

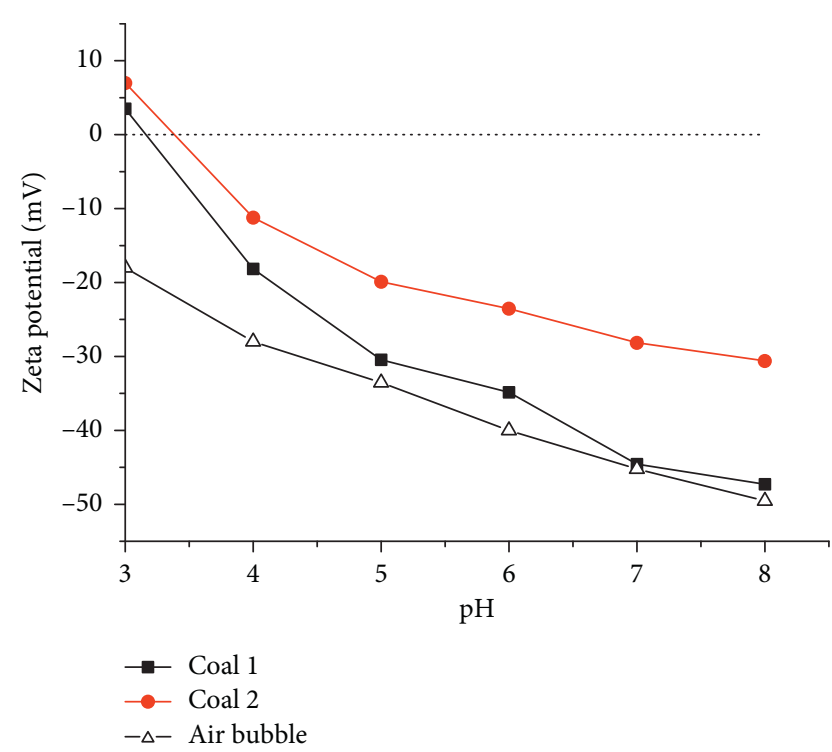

FIgURE 4: Zeta potential measurements versus $\mathrm{pH}$ solutions for two coal samples and air bubble.

noted that the zeta potential of air bubble is available in [26]. As can be seen, the zeta potential of coal particles decreased steadily with $\mathrm{pH}$. This is because the ionizable groups including phenolic hydroxyl groups and carboxyl groups on coal surfaces can adsorb $\mathrm{H}^{+}$at low $\mathrm{pH}$ but release $\mathrm{H}^{+}$at high $\mathrm{pH}[7,27]$. Figure 4 shows that the zeta potential of Coal 2 is higher than that of Coal 1. In addition, the IEP of Coal 1 and Coal 2 located at $\mathrm{pH} 3.3$ and 3.6, respectively, while the zeta potential of Coal 1 at $\mathrm{pH} 4$ decreased sharper than that of Coal 2, which indicates that the content of ionizable groups on the Coal 1 surface was higher than that on Coal 2. In the literature, it has been reported the air bubbles are negatively charged at higher $\mathrm{pH}$ due to the preferential adsorption of $\mathrm{OH}^{+}$ions $[26,28,29]$. Therefore, Coal 1 particles and air bubbles are more negatively charged in DI water, and the electrostatic repulsion is expected between them, which is unfavorable for bubble-particle collision and attachment, while favorable for the wetting process inversely. Therefore, the deep burial metamorphism might be unfavorable for the wetting process.

3.4. Contact Angle Measurements. The representative pictures of contact angles of two coal samples are shown in Figure 5. The results of each contact angle were acquired using the average of three independent measurements. The contact angle of Coal 1 is about $73.9^{\circ}$, while the contact angle of Coal 2 is $82.1^{\circ}$. The fact that the contact angle of Coal 1 is less than that of the Coal 2 convincingly indicated that the surface of Coal 1 is more hydrophilic than that of Coal 2. The results of contact angle correspond well with the XPS and FTIR results. For the wet dust removal method, the dedusting effects of Coal 1 would be more significant than those of Coal 2.

3.5. DLVO Theory for Coal Bubble-Particle Interaction. The DLVO theory is utilized to compute the interaction energy of these two coal samples and air bubbles under various $\mathrm{pH}$ values, which can be formulated as

$$
E=E_{v d w}+E_{e d l}
$$

The van der Waals (vdW) interactions consist of the London interaction, the Keesom interaction, and the Debye interaction [30]. The Hamaker approach could be employed to model the particle-bubble interaction [31, 32]. Based on the Hamaker theory, the van der Waals (vdW) interactions can be expressed as

$$
E_{v d w}=-\frac{R_{b} R_{p} A_{132}}{6\left(R_{b}+R_{p}\right) h},
$$

where $R_{p}$ and $R_{b}$ are the radius of particles and bubbles, respectively; $A_{132}$ is the Hamaker constant for the particlebubble interaction immersed in the solution [33].

The EDL interactions originate from the overlapping of electrical double layers of particle and bubble. The Poisson-Boltzmann equation can be used to calculate the EDL disjoining pressure [30]. When both particle and bubble have constant surface potentials, the EDL interaction energy can be given as

$$
E_{\text {edl }}=\frac{\varepsilon \varepsilon_{0} \pi R_{b} R_{p}}{R_{b}+R_{p}}\left[4 \psi_{1} \psi_{2} \arctan h\left(e^{-\mathrm{kh}}\right)+\left(\psi_{1}^{2}+\psi_{2}^{2}\right) \ln \left(1-e^{-2 \mathrm{kh}}\right)\right],
$$

where $\psi_{1}$ and $\psi_{2}$ indicate the surface potential of a particle and bubble, respectively; $\varepsilon$ is the dielectric constant; $\kappa-1$ is the Debye length; the shortest distance between them is $h$; and $\varepsilon 0$ is the vacuum permittivity.

Noticeably, electrostatic repulsive energy is much greater than the London-van der Waals attractive energy, resulting in energy barriers. The energy barriers calculated by the DLVO theory imply the degree of difficulty when the particle-bubble contact occurs. 


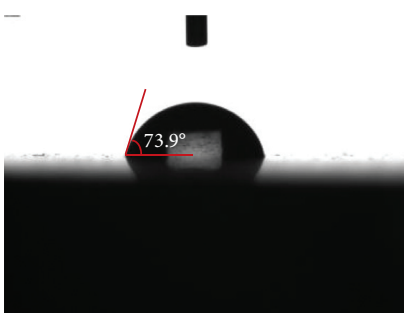

(a)

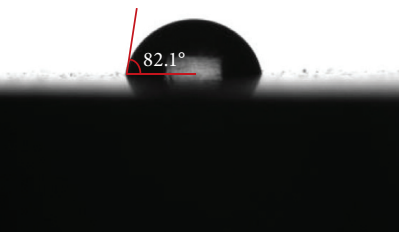

(b)

Figure 5: Contact angles of two coal samples. (a) Coal 1. (b) Coal 2.

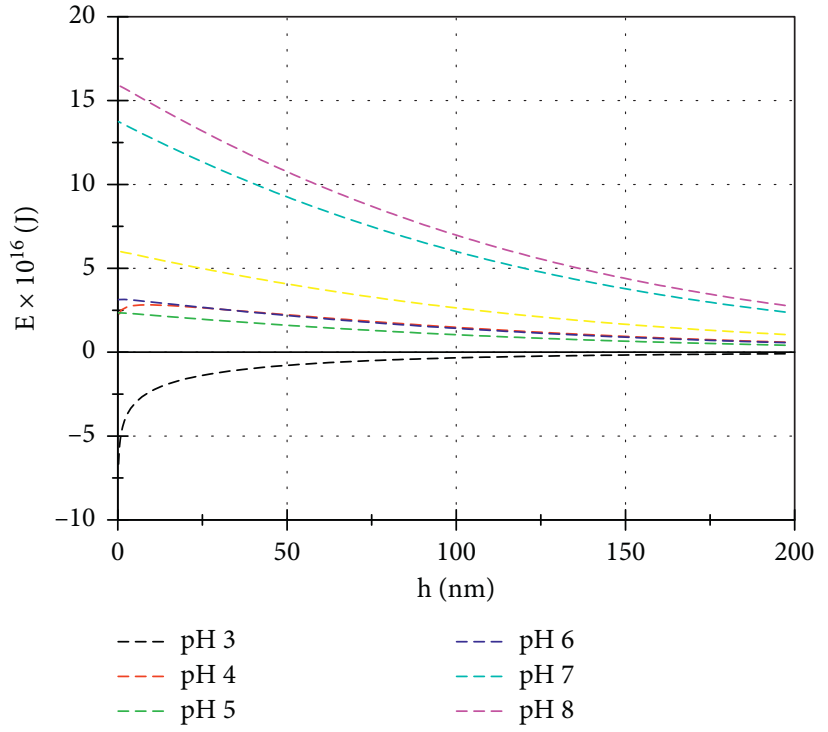

(a)

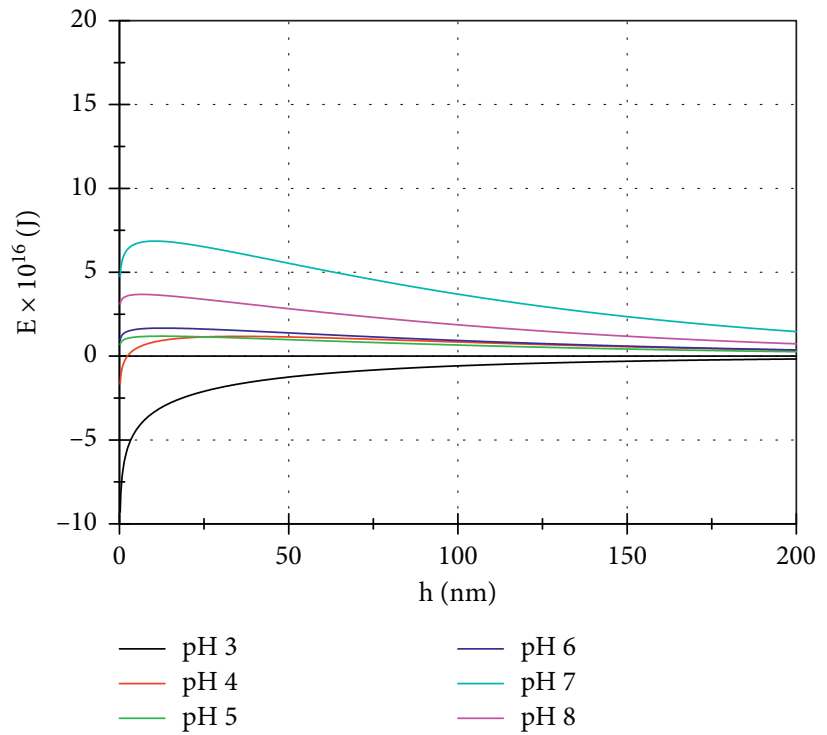

(b)

Figure 6: DLVO interaction energy between (a) Coal 1 particle and an air bubble and (b) Coal 2 particle and an air bubble at different pH values.

Figure 6 displays the total interaction energy between the two coal samples and air bubbles under different $\mathrm{pH}$ values, while Figure 7 shows their corresponding energy barriers.

It shows that during the $\mathrm{pH}$ range of 3-8, the energy barriers between Coal 1 particles and air bubbles are higher than those between Coal 2 particles and air bubbles. As a result, it can be quantitatively concluded that the hydrophobicity of coal 2 particle is stronger than coal 1 particle. Also, for the deep coal sample, the bubble-particle interaction would be easier to happen because of the lower energy barriers, while the wetting process of deep coal tends to be more difficult inversely.

\section{Conclusions}

In this work, the superficial and deep coal samples were selected to simulate the deep burial metamorphism process. The surface properties of two coal samples were comparatively studied by X-ray photoelectron spectroscopy (XPS), FTIR, zeta potential, contact angle measurements, and DLVO theory. In terms of the aforementioned experimental results and detailed analysis, the following conclusions could be drawn:

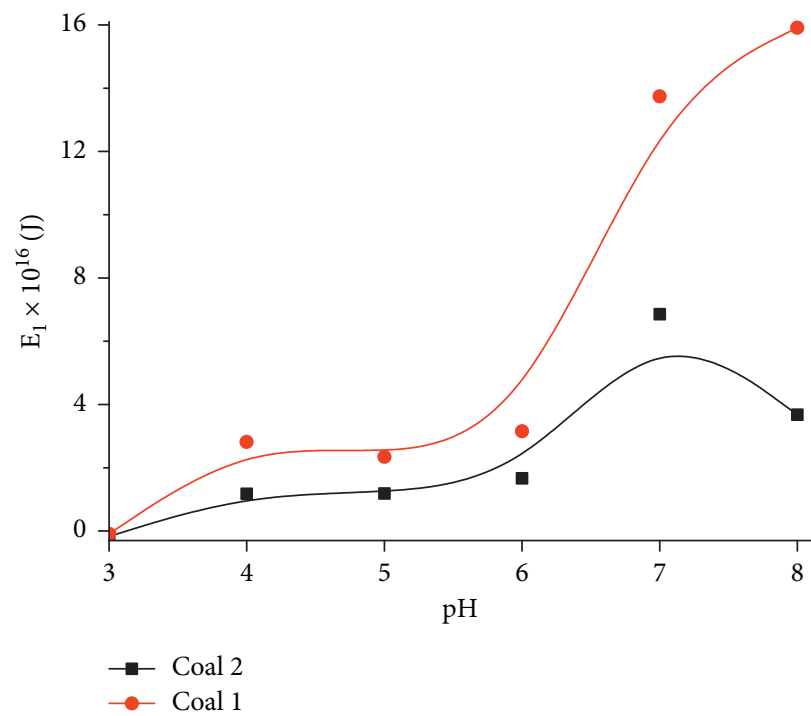

FIGURE 7: Energy barriers for the coal samples and air bubble at different $\mathrm{pH}$ values. 
(1) The XPS and FTIR results indicate that the content of the surface oxygen atom and oxygen-containing functional group for superficial coal is much higher than that of deep coal, indicating the deep burial metamorphism might increase the hydrophobicity of coal.

(2) The zeta potential measurements and DLVO theory analyses indicated that for the deep coal sample, the particle-bubble interaction would be easier to happen because of the lower energy barriers, while the wetting process of deep coal tends to be more difficult inversely.

Based on the investigation of surface chemistry and theory analyses of superficial and deep coal samples, the deep burial metamorphism might be favorable for bubbleparticle collision and attachment because of the lower energy barriers and thus increases the efficient coal processing or beneficiation, while it might be unfavorable for the wetting process and thus decreases the efficient coal dedusting process during mining inversely. This study is expected to give a theoretical insight into the efficient processing or dedusting process of coals experiencing different deep burial metamorphism processes in the future.

\section{Data Availability}

The data used to support the findings of this study are available from the corresponding author upon request.

\section{Conflicts of Interest}

The authors declare no conflicts of interest regarding the publication of this paper.

\section{Acknowledgments}

This work was supported by the Science and Technology Innovation Program of Higher Education Institutions Shanxi Province, Shanxi Province Science Foundation for Youths (Grant no. 2015021120).

\section{References}

[1] Y. Cheng and Z. Pan, "Reservoir properties of Chinese tectonic coal: a review," Fuel, vol. 260, Article ID 116350, 2020.

[2] X. Wang, S. Yuan, and B. Jiang, "Experimental investigation of the wetting ability of surfactants to coals dust based on physical chemistry characteristics of the different coal samples," Advanced Powder Technology, vol. 30, no. 8, pp. 1696-1708, 2019.

[3] R. Si, "Research status and development trend of gas and coal dust explosion," Mining Safety and Environmental Protection, vol. 41, pp. 72-75, 2014.

[4] W. Xia and G. Xie, "Comparison of surface properties of anthracite coals before and after high temperature heating process," Physicochemical Problems of Mineral Processing, vol. 51, no. 1, pp. 205-212, 2015.

[5] W. Xia and J. Yang, "Changes in surface properties of anthracite coal before and after inside/outside weathering processes," Applied Surface Science, vol. 313, pp. 320-324, 2014.

[6] W. Xia, J. Yang, and C. Liang, "Effect of microwave pretreatment on oxidized coal flotation," Powder Technology, vol. 233, pp. 186-189, 2013.

[7] W. Xia, J. Yang, Y. Zhao, B. Zhu, and Y. Wang, "Improving floatability of Taixi anthracite coal of mild oxidation by grinding," Physicochemical Problems of Mineral Processing, vol. 48, pp. 393-401, 2012.

[8] M. S. Jena, S. K. Biswal, and M. V. Rudramuniyappa, "Study on flotation characteristics of oxidised Indian high ash subbituminous coal," International Journal of Mineral Processing, vol. 87, no. 1-2, pp. 42-50, 2008.

[9] W. Xia and J. Yang, "Enhancement in flotation of oxidized coal by oxidized diesel oil and grinding pretreatment," International Journal of Coal Preparation and Utilization, vol. 33, no. 6, pp. 257-265, 2013.

[10] G. Zhou, W. M. Cheng, G. Wang, and L. J. Chen, "Optimal design of dust-settling device by water spraying for powered support in fully mechanized caving face annually producing 6 million tons of coal," Journal of Shandong University of Science and Technology (Natural Science), vol. 28, 2009.

[11] J. A. Gutierrez-Rodriguez, R. J. Purcell, Jr., and F. F. Aplan, "Estimating the hydrophobicity of coal," Colloids and Surfaces, vol. 12, pp. 1-25, 1984.

[12] H. W. Kilau and J. E. Pahlman, "Coal wetting ability of surfactant solutions and the effect of multivalent anion additions," Colloids and Surfaces, vol. 26, pp. 217-242, 1987.

[13] P. J. Scales, F. Grieser, D. N. Furlong, and T. W. Healy, "Contact angle changes for hydrophobic and hydrophilic surfaces induced by nonionic surfactants," Colloids and Surfaces, vol. 21, pp. 55-68, 1986.

[14] J. O. Glanville and L. H. Haley, Jr., "The wetting of "nuisance" dusts by surfactant solutions," Colloids and Surfaces, vol. 8, no. 1, pp. 93-97, 1983.

[15] J. O. Glanville and L. H. Haley, "Studies of coal dust wetting by surfactant solutions," Colloids and Surfaces, vol. 4, no. 3, pp. 209-212, 1982.

[16] J. O. Glanville and J. P. Wightman, "Actions of wetting agents on coal dust," Fuel, vol. 58, no. 11, pp. 819-822, 1979.

[17] F. O. Orumwense, "Estimation of the wettability of coal from contact angles using coagulants and flocculants," Fuel, vol. 77, pp. 1107-1111, 1998.

[18] Y. Wang, Y. Cao, G. Li, Y. Liao, Y. Xing, and X. Gui, "Combined effect of chemical composition and spreading velocity of collector on flotation performance of oxidized coal," Powder Technology, vol. 325, pp. 1-10, 2018.

[19] S. Chen, L. Tang, X. Tao, L. Chen, Z. Yang, and L. Li, "Effect of oxidation processing on the surface properties and floatability of Meizhiyou long-flame coal," Fuel, vol. 210, pp. 177-186, 2017.

[20] X. Duan and Z. Wang, "XPS analysis of oxygen contained functional group in coal macerals," Journal of Liaoning Technical University (Natural Science), vol. 29, pp. 498-501, 2010.

[21] S. S. Drake, D. M. O’Carroll, and J. I. Gerhard, "Wettability contrasts between fresh and weathered diesel fuels," Journal of Contaminant Hydrology, vol. 144, no. 1, pp. 46-57, 2013.

[22] G. Pan, Q. Huang, H. Hu, and Z. Liu, "Wettability of superhydrophobic surface through tuning microcosmic structure," Polymeric Materials Science and Engineering, vol. 26, pp. 163-166, 2010. 
[23] W. Xia, G. Xie, and Y. Peng, "Comparison of flotation performances of intruded and conventional coals in the absence of collectors," Fuel, vol. 164, pp. 186-190, 2016.

[24] Z. Chang, X. Chen, and Y. Peng, "The effect of saline water on the critical degree of coal surface oxidation for coal flotation," Minerals Engineering, vol. 119, pp. 222-227, 2018.

[25] R.-H. Yoon and L. Mao, "Application of extended DLVO theory, IV," Journal of Colloid and Interface Science, vol. 181, no. 2, pp. 613-626, 1996.

[26] C. Yang, T. Dabros, D. Li, J. Czarnecki, and J. H. Masliyah, "Measurement of the zeta potential of gas bubbles in aqueous solutions by microelectrophoresis method," Journal of Colloid and Interface Science, vol. 243, no. 1, pp. 128-135, 2001.

[27] M. Sarikaya and G. Özbayoğlu, "Flotation characteristics of oxidized coal," Fuel, vol. 74, no. 2, pp. 291-294, 1995.

[28] A. S. Najafi, J. Drelich, A. Yeung, Z. Xu, and J. Masliyah, "A novel method of measuring electrophoretic mobility of gas bubbles," Journal of Colloid and Interface Science, vol. 308, no. 2, pp. 344-350, 2007.

[29] A. Graciaa, G. Morel, P. Saulner, J. Lachaise, and R. S. Schechter, "The $\zeta$-potential of gas bubbles," Journal of Colloid and Interface Science, vol. 172, no. 1, pp. 131-136, 1995.

[30] A. V. Nguyen, H. J. Schulze, A. V. Nguyen, and H. J. Schulze, "Colloidal science of flotation," Colloidal Science of Flotation, vol. 118, pp. 1-850, 2004.

[31] J. N. Israelachvili, "Intermolecular and surface forces," The Quarterly Review of Biology, vol. 2, pp. 59-65, 2011.

[32] T. Miettinen, J. Ralston, and D. Fornasiero, "The limits of fine particle flotation," Minerals Engineering, vol. 23, no. 5, pp. $420-437,2010$.

[33] J. Laskowski and J. A. Kitchener, "The hydrophilic-hydrophobic transition on silica," Journal of Colloid and Interface Science, vol. 29, no. 4, pp. 670-679, 1969. 